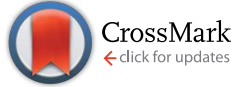

Cite this: Chem. Sci., 2015, 6, 7105

\title{
Metal-organic framework composites with luminescent gold(III) complexes. Strongly emissive and long-lived excited states in open air and photo- catalysis $\uparrow$
}

\author{
Chun-Yi Sun,,$^{\mathrm{ab}}$ Wai-Pong To, t. $^{\mathrm{a}}$ Xin-Long Wang, ${ }^{\mathrm{b}}$ Kaai-Tung Chan, ${ }^{\mathrm{a}}$ Zhong-Min Su \\ and Chi-Ming Che ${ }^{\star a c}$
}

The encapsulation of luminescent gold(III) complexes by metal-organic frameworks (MOFs) lays the groundwork for new phosphorescent materials with activities that are not readily achieved by the host MOF materials or gold(III) complexes alone. In this work, strong phosphorescence with lifetimes of up to $\sim 50 \mu \mathrm{s}$ in open air at room temperature has been achieved by incorporation of cationic cyclometalated gold(III) complexes into MOFs with anionic frameworks to form Au'"aMOFs. The Au III aMOFs display solid state two-photon-induced phosphorescence. Photo-reduction of methyl viologen to the reduced radical was achieved inside $\mathrm{Au}$ "' $\mathrm{CMOFs}$ and in the presence of $\mathrm{Et}_{3} \mathrm{~N}$ upon excitation at $\lambda>370 \mathrm{~nm}$ under ambient conditions. These $\mathrm{Au}^{\prime \prime \prime}$ (aMOFs comprise a class of reusable and size-selective heterogeneous photo-catalysts for the aerobic oxidation of secondary amines to imines as well as five other reactions, including oxidative $\mathrm{C}-\mathrm{H}$ functionalization under aerobic conditions.

Received 19th June 2015

Accepted 4th September 2015

DOI: $10.1039 / \mathrm{c} 5 \mathrm{sc0} 02216 \mathrm{a}$

www.rsc.org/chemicalscience

functions/performance of the encapsulated guest species may emerge.

We are attracted to using MOFs for housing metal complexes with long-lived emissive excited states for heterogeneous photochemical catalysis and luminescence applications. In the literature, other porous materials besides MOFs, such as mesoporous silica, have also been employed to encapsulate photoluminescent and/or photochemically active compounds, ${ }^{5,6}$ including confinement of a photoluminescent trinuclear gold(I) pyrazolate complex in the channels of mesoporous silica. ${ }^{b b}$ Our attention has been directed towards recently reported luminescent gold(III) complexes which display strongly emissive excited states with long lifetimes of up to $506 \mu \mathrm{s}$ (emission quantum yields: up to $11.4 \%$ ) in degassed solutions at room temperature. ${ }^{7}$ These complexes may have useful applications in photo-catalysis and emission sensing, particularly if they are located in an aerobic environment in which their photo-physical characteristics can be retained, and if the photochemical reactions they catalyse can be endowed with specificity. Here we report our findings on the encapsulation of strongly luminescent gold(III) complexes with various dimensions (Au1-Au4, ${ }^{7,8}$ Scheme 1; Table S1 in the ESI $\dagger$ ) by two MOFs with differing porous structures. The encapsulation was performed using a cation exchange method. ${ }^{4 a, 9}$ The $\mathrm{Au}^{\text {III }}$-MOF composites ( $\left.\mathrm{Au}^{\mathrm{III}} @ \mathrm{MOFs}\right)$ display long emission lifetimes of up to $48.8 \mu \mathrm{s}$ at room temperature and in open air, exhibit solid state twophoton-induced phosphorescence, and can act as selective and recyclable catalysts for light-induced electron transfer reactions
State Key Laboratory of Synthetic Chemistry, Institute of Molecular Functional Materials, HKU-CAS Joint Laboratory on New Materials, Department of Chen The University of Hong Kong, Pokfulam Road, Hong Kong, China. E-mail: cmche@ ${ }^{b}$ Institute of Functional Materials Chemistry, Northeast Normal University, Changchun, Jilin, 130024, China

${ }^{c} H K U$ Shenzhen Institute of Research and Innovation, Shenzhen, 518053, China

$\dagger$ Electronic supplementary information (ESI) available: Synthesis and characterization data, photo-catalytic studies, and supplementary figures/tables. X-ray crystallographic data of MOF1. CCDC 993259. For ESI and crystallographic data in CIF or other electronic format see DOI: $10.1039 / \mathrm{c} 5 \mathrm{sc} 02216 \mathrm{a}$

\$ These authors contributed equally to this work. 


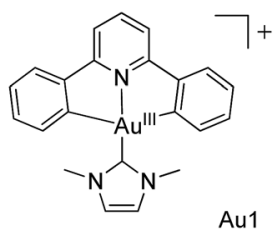

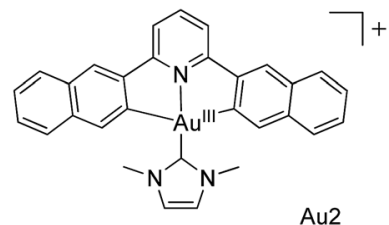
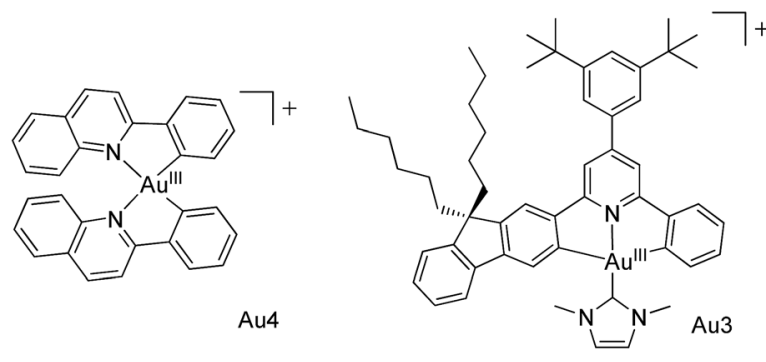

Scheme $1 \mathrm{Au} u^{\text {III }}$ complexes Au1-Au4 used in this work.

and aerobic $\mathrm{C}-\mathrm{N} / \mathrm{C}-\mathrm{C} / \mathrm{C}-\mathrm{O}$ bond forming reactions. Of note, Corma and co-workers ${ }^{10}$ have described a recyclable $\mathrm{Au}^{\text {III- }}$ functionalized MOF catalyst for domino coupling/cyclization and alkene hydrogenation, prepared by post-synthetic dative bond formation.

\section{Results and discussion}

\section{Syntheses and structures of MOF1 and MOF2}

Two MOFs, MOF1 and MOF2, built from similar ligands but possessing different types of pores with suitable window sizes, were chosen in this work to allow investigation of the effect of porous structure on the luminescence of $\mathrm{Au}$ (III) complexes.

MOF1, formulated as $\left[\mathrm{Me}_{2} \mathrm{NH}_{2}\right]_{2}\left[\mathrm{Cd}_{2}(\mathrm{TATMB})_{2}\right] \cdot 10 \mathrm{DMF} \cdot 3 \mathrm{H}_{2}-$ $\mathrm{O}\left(\mathrm{H}_{3}\right.$ TATMB $=3,3^{\prime}, 3^{\prime \prime}$-((1,3,5-triazine-2,4,6-triyl)tris(azanediyl) tribenzoic acid) based on single-crystal X-ray diffraction, elemental analysis, thermogravimetric analysis (TGA), and charge-balance consideration, was obtained as colourless rodlike crystals by the reaction of $\mathrm{H}_{3}$ TATMB with $\mathrm{Cd}\left(\mathrm{NO}_{3}\right)_{2} \cdot 6 \mathrm{H}_{2} \mathrm{O}$ in $\mathrm{DMF}$ at $120{ }^{\circ} \mathrm{C}$ for 2 days (the $\left[\mathrm{Me}_{2} \mathrm{NH}_{2}\right]^{+}$cations came from decarbonylation of $\mathrm{DMF}^{11}$ ). The phase purity of MOF1 was examined by powder X-ray diffraction (PXRD) analysis.

Single-crystal X-ray structure determination of MOF1 revealed a 3D framework (Fig. 1a) that can be described as a 4-connected uninodal net with hxg-d-4-C2/m topology ${ }^{12}$ (Fig. S1d, ESI $\dagger$ ). The asymmetric unit contains one crystallographically independent $\mathrm{Cd}^{2+}$ ion and one TATMB ligand (the other cations and guest molecules are disordered and have not been precisely defined). The $\mathrm{Cd}^{2+}$ ion is seven-coordinated by six carboxylate oxygen atoms of three TATMB ligands and one $\mathrm{N}$ atom from the triazine ring of another TATMB ligand; each pair of nearest-neighbour $\mathrm{Cd}^{2+}$ ions are bridged by two TATMB ligands to form an 18-membered ring (Fig. S1a, ESI $\dagger$ ). There are large nano-scale tubular channels (window size: $17 \times 24 \AA^{2}$, Fig. 1b) running along the [023] plane, with solvent molecules and $\left[\mathrm{Me}_{2} \mathrm{NH}_{2}\right]^{+}$ions residing in the channels. The effective free volume of MOF1 is $70.7 \%$ of the crystal volume (calculated by PLATON analysis ${ }^{13}$ ). The TGA data (Fig. S2, ESI $\dagger$ ) revealed a decrease in weight of $38.4 \%$, attributed to a loss of solvent and

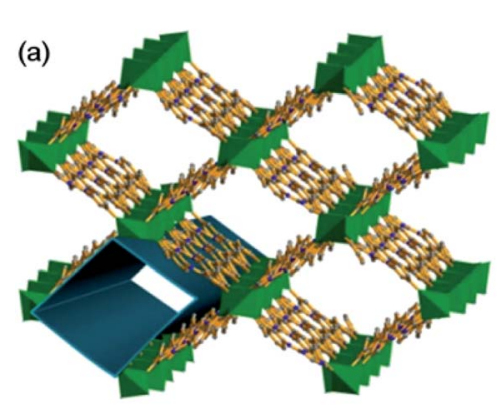

(b)

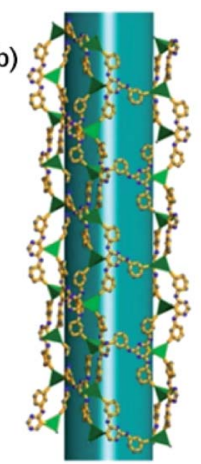

(c)

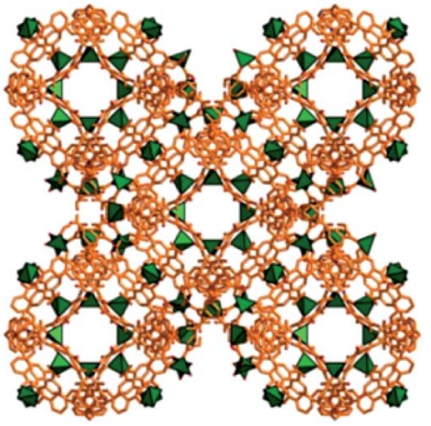

(d)

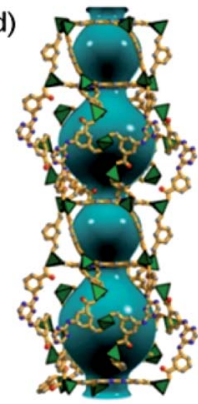

Fig. 1 (a) 3D polyhedral structure of MOF1, viewed along the $c$ axis; (b) 1D mesoporous nanotube component of MOF1; (c) 3D polyhedral structure of MOF2, viewed along the a axis; (d) trigonal and hexagonal prism-shaped nanocages in MOF2.

water molecules; the de-solvated framework remained stable until $\sim 290{ }^{\circ} \mathrm{C}$ (above this temperature the framework began to decompose and the final residue was $\mathrm{CdO}[6.32 \%$ observed, $6.20 \%$ calculated]). $\mathrm{N}_{2}$ adsorption measurements for MOF1 revealed an isotherm (Fig. S3, ESI $\dagger$ ) which corresponds to a Type 1 adsorption isotherm for porous materials. ${ }^{14}$

MOF2, $\quad\left[\mathrm{Me}_{2} \mathrm{NH}_{2}\right]_{2}\left[\mathrm{Zn}(\mathrm{TATAT})_{2 / 3}\right] \cdot 3 \mathrm{DMF} \cdot \mathrm{H}_{2} \mathrm{O} \quad(\mathrm{TATAT}=$ $5,5^{\prime}, 5^{\prime \prime}$-(1,3,5-triazine-2,4,6-triyl)tris(azanediyl)triisophthalate), was prepared according to the literature..$^{15}$ MOF2 has a 3D mesocage structure (Fig. 1c) featuring alternately arranged hexagonal prismatic cages (window size: $6.3 \times 10.5 \AA^{2}$ ) and trigonal prismatic cages (window size: $14.3 \times 11.5 \AA^{2}$ ) (Fig. 1d), with a potential solvent volume that accounts for $60 \%$ of the empty volume. ${ }^{15}$ The $\left[\mathrm{Me}_{2} \mathrm{NH}_{2}\right]^{+}$cations and $\mathrm{DMF} / \mathrm{H}_{2} \mathrm{O}$ molecules reside in these nano-scale cages.

\section{Syntheses, characterization and photo-physical properties of} Au'IIOMOF composites

$\mathrm{Au}^{\mathrm{III}} @$ @OFs, including Au ${ }^{\mathrm{III}} @ \mathrm{MOF} 1\left(\mathrm{Au}^{\mathrm{III}}=\mathrm{Au} 1-\mathrm{Au} 4\right)$ and $\mathrm{Au}^{\mathrm{III}} @ \mathrm{MOF} 2\left(\mathrm{Au}^{\mathrm{III}}=\mathrm{Au} 1, \mathrm{Au} 2\right)$, were obtained as yellow or pale yellow solids (Fig. S4, ESI $\dagger$ ) by immersing MOF1 or MOF2 in a DMF solution of the $\mathrm{CF}_{3} \mathrm{SO}_{3}{ }^{-}$or $\mathrm{BF}_{4}{ }^{-}$salt of the corresponding $\mathrm{Au}^{\text {III }}$ complex for several days. The incorporated $\mathrm{Au}^{\text {III }}$ complexes, comprising $0.91-8.26$ wt $\%$ of the $\mathrm{Au}^{\mathrm{III}} @ \mathrm{MOF}$ (determined by inductively coupled plasma (ICP) spectroscopy, Table S2, ESI $†$ ), are likely to reside in the inner pores of the MOF host materials based on the following: (i) the MOF hosts of these AuII@MOFs contain nanochannels/nanocages with window sizes larger than the sizes of the incorporated $\mathrm{Au}^{\text {III }}$ 
complexes (Table S1, ESI $\dagger$ ); (ii) complex Au3, which is larger than the window sizes of the nano-cages in MOF2, did not give Au3@MOF2 (under similar conditions the MOF2 in the reaction mixture remained colourless, and ICP analysis revealed no Au3 incorporation into MOF2), suggesting that adsorption of the $\mathrm{Au}^{\mathrm{III}}$ complex outside the pores (or in gaps/cracks between crystal grains) of the MOF is negligible; (iii) the PXRD data of the $\mathrm{Au}^{\text {III } @ M O F s ~ w e r e ~ n e a r l y ~ i d e n t i c a l ~ t o ~ t h o s e ~ o f ~ t h e ~ c o r r e s p o n d i n g ~}$ MOF matrices (Fig. S5, ESI†); (iv) examination of the cross section of a crystal of Au2@MOF2 (1.43 wt\% Au2) by optical microscopy under UV light irradiation at $365 \mathrm{~nm}$ showed the characteristic yellowish green emission of Au2 (ref. 7), congruent with incorporation of Au2 inside the crystal (Fig. S8, ESI $†$ ); (v) further analysis of the cross section of Au2@MOF2 by scanning electron microscopy (SEM) and electron dispersive X-ray spectroscopy (EDX) revealed that Au2 was disorderedly dispersed at the cross section (Fig. S9, ESI $\dagger$ ) and that no F was detected in Au2@MOF2 by EDX, even when the content of incorporated $\mathrm{Au} 2$ increased from 1.43 to $8.26 \mathrm{wt} \%$ (Fig. S10, ESI $\dagger$ ); (vi) $\mathrm{N}_{2}$ adsorption experiments (Fig. S11, ESI $\dagger$ ) showed that, from free MOF2 to Au2@MOF2 (1.43 wt\% Au2), the pore volume decreased from 0.303 to $0.276 \mathrm{~cm}^{3} \mathrm{~g}^{-1}$, with a decrease in BET surface area from 1112 to $1011 \mathrm{~m}^{2} \mathrm{~g}^{-1}$. Increasing the $\mathrm{Au} 2$ content of Au2@MOF2 to $8.26 \mathrm{wt} \%$ led to a reduction in the pore volume and BET surface area to $0.183 \mathrm{~cm}^{3} \mathrm{~g}^{-1}$ and $656 \mathrm{~m}^{2}$ $\mathrm{g}^{-1}$, respectively. The decreases in the pore volume and BET surface area are attributed to the encapsulation of Au2 in the pores of MOF2.AuIII@MOFs display strong emission under air at room temperature. As depicted in their emission spectra (Fig. 2), two emission bands are observed. The one at $\sim 450 \mathrm{~nm}$
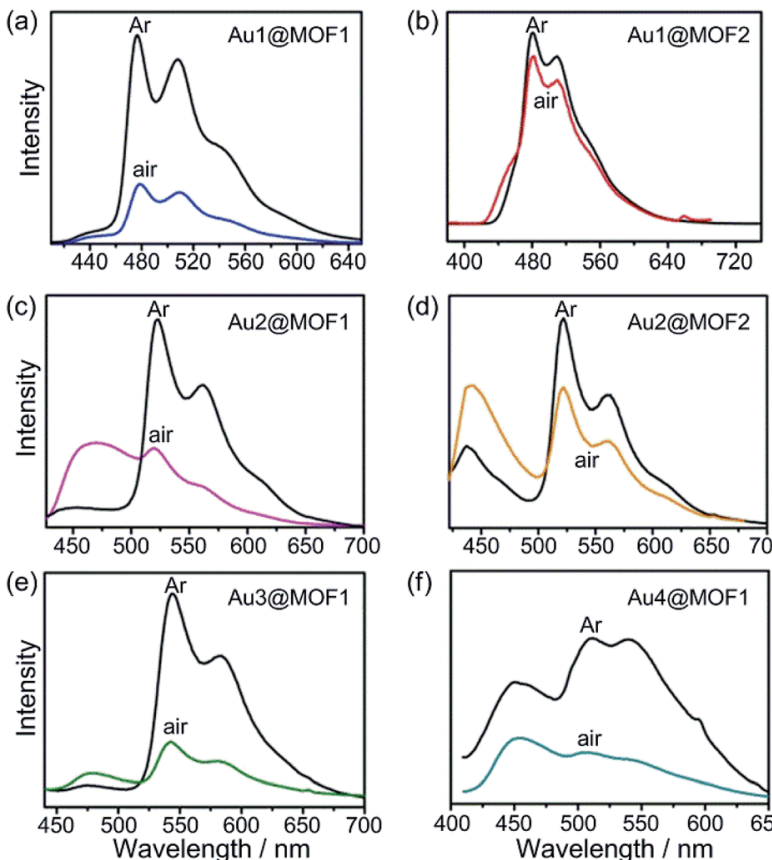

(d)
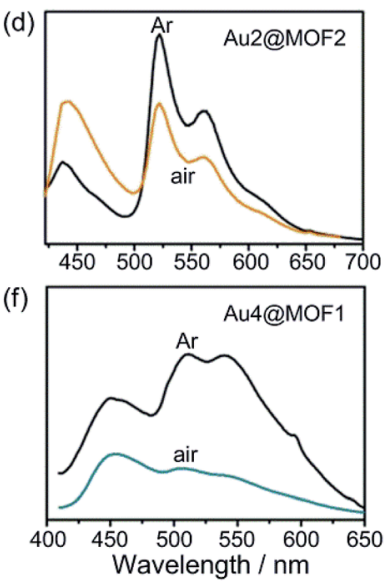

Fig. 2 Emission spectra of Au'l' aMOFs in Ar (black lines) and air (color lines) upon excitation at $\lambda=365 \mathrm{~nm}$ at room temperature. (a) Au1@MOF1; (b) Au1@MOF2; (c) Au2@MOF1; (d) Au2@MOF2; (e) Au3aMOF1; (f) Au4@MOF1. corresponds to the MOF host. The other is a vibronic structured emission with peak $\lambda_{\max }$ at $478-550,520-610,540-630$ and 510-580 $\mathrm{nm}$ for $\mathrm{Au}^{\mathrm{III}}=\mathrm{Au} 1, \mathrm{Au} 2, \mathrm{Au} 3$ and $\mathrm{Au} 4$, respectively. These bands are all similar to those observed in the emission spectra of the corresponding $\mathrm{Au}^{\mathrm{III}}$ complexes in degassed solution. ${ }^{7,8}$ The measured emission lifetimes $\left(\tau_{0}\right)$, quantum yields $\left(\phi_{\mathrm{em}}\right)$, and estimated radiative $\left(k_{\mathrm{r}}\right)$ and non-radiative $\left(k_{\mathrm{nr}}\right)$ decay rate constants of $\mathrm{Au}^{\mathrm{III}} @ \mathrm{MOFs}$ and $\mathrm{Au} 1-\mathrm{Au} 4$ under different conditions are compiled in Table 1.

Encapsulation of Au1-Au4 by MOF1 or MOF2 was observed to cause significant increases in the intensity and lifetime of the emission of these $\mathrm{Au}^{\mathrm{III}}$ complexes (Fig. 2 and Table 1; Fig. S6 and S7, ESI $†$ ). As an example, at room temperature, Au2 is nonemissive in the solid state, and the intensity of its emission at $520 \mathrm{~nm}$ in degassed dichloromethane solution decreased more than 100-fold upon exposure of the solution to air. ${ }^{7}$ Remarkably, Au2@MOF2 is luminescent under aerobic conditions, ${ }^{16}$ and the quantum yield decreased only $\sim 5$-fold compared with that measured under argon (Table 1). For Au2@MOF1 and Au4@MOF1, the decrease in emission quantum yield on changing the atmosphere from argon to air is $\sim 10$ - and $\sim 20$-fold, respectively. Moreover, while Au2 is virtually nonemissive in DMF solution in air, Au2@MOF2 (1.43 wt\% Au2), Au2@MOF2 (8.26 wt\% Au2), and Au2@MOF1 are luminescent in air, with emission lifetimes of 14.5, 15.8, and $7.9 \mu \mathrm{s}$, respectively. Notably, the emission lifetime of Au1@MOF2 in air is $19.4 \mu \mathrm{s}$, which is $>60$-fold longer than that of Au1 in the solid state $(0.20 \mu \mathrm{s})$ and in DMF solution $(0.32 \mu \mathrm{s})$ under aerobic conditions (Table 1). ${ }^{17}$ The emission lifetime of Au3@MOF1 in open air is $48.8 \mu \mathrm{s}$, the longest emission lifetime reported for luminescent $\mathrm{Au}^{\text {III }}$ complexes under aerobic conditions. Compared with Au ${ }^{\text {III } @ M O F 2, ~ t h e ~ A u ' ~}{ }^{\text {III } @ M O F 1 ~ c o m p o s i t e s ~ a r e ~}$ more susceptible to luminescence quenching under aerobic conditions (Fig. 2 and Table 1), due probably to the larger window size of the pores in MOF1 than in MOF2. The intrinsic triplet excited state properties and molecular sizes of the $\mathrm{Au}^{\mathrm{III}}$ complexes could also affect the luminescence quenching behaviour of $\mathrm{Au}^{\mathrm{III}} @ \mathrm{MOFs}$ upon exposure to air. The elevated intensities and lifetimes of the emissions of Au ${ }^{\mathrm{III}} @ M O F s$ in the solid state under aerobic conditions are attributed to the following: (i) the emission lifetimes of $\mathrm{Au}^{\mathrm{III}} @ \mathrm{MOFs}$ under argon are longer, and their non-radiative decay rate constants $\left(k_{\mathrm{nr}}\right)$ are smaller, than those of the corresponding $\mathrm{Au}^{\mathrm{III}}$ complexes in degassed solution (Table 1). Electrostatic binding of the $\mathrm{Au}^{\text {III }}$ complexes on the surfaces of the inner pores of the MOFs would restrict the molecular motion of the $\mathrm{Au}^{\mathrm{III}}$ complexes, thereby slowing down non-radiative decay and self-quenching (by diffusion) of the emissive excited state. ${ }^{18}$ The radiative decay rate constants $\left(k_{\mathrm{r}}\right)$ of $\mathrm{Au}^{\mathrm{III}} @ \mathrm{MOFs}$ and $\mathrm{Au} 1-\mathrm{Au} 4$ are in the order of $10^{2}$ to $10^{3} \mathrm{~s}^{-1}$ (Table 1), typical of ${ }^{3} \mathrm{IL}$ excited states of luminescent gold(III) complexes. ${ }^{8 a}$ (ii) The steady state concentration of oxygen in the pores of Au ${ }^{\mathrm{III}} @$ MOFs may be lower than that of the oxygen dissolved in the solvent and in free atmosphere. This may reduce oxygen quenching of the emission of $\mathrm{Au}^{\mathrm{III}} @ \mathrm{MOF}$ in air. ${ }^{19}$ Given that the activity of $\mathrm{O}_{2}$ in the matrix would equal that in the external environment if the matrix and the ambient environment are at equilibrium, and considering the use of $\mathrm{O}_{2}$ 
Table 1 Emission lifetimes, quantum yields, and radiative and non-radiative decay rate constants of the $\mathrm{Au}^{\text {III }}$ complexes and $\mathrm{Au}$ 'IIMOFs

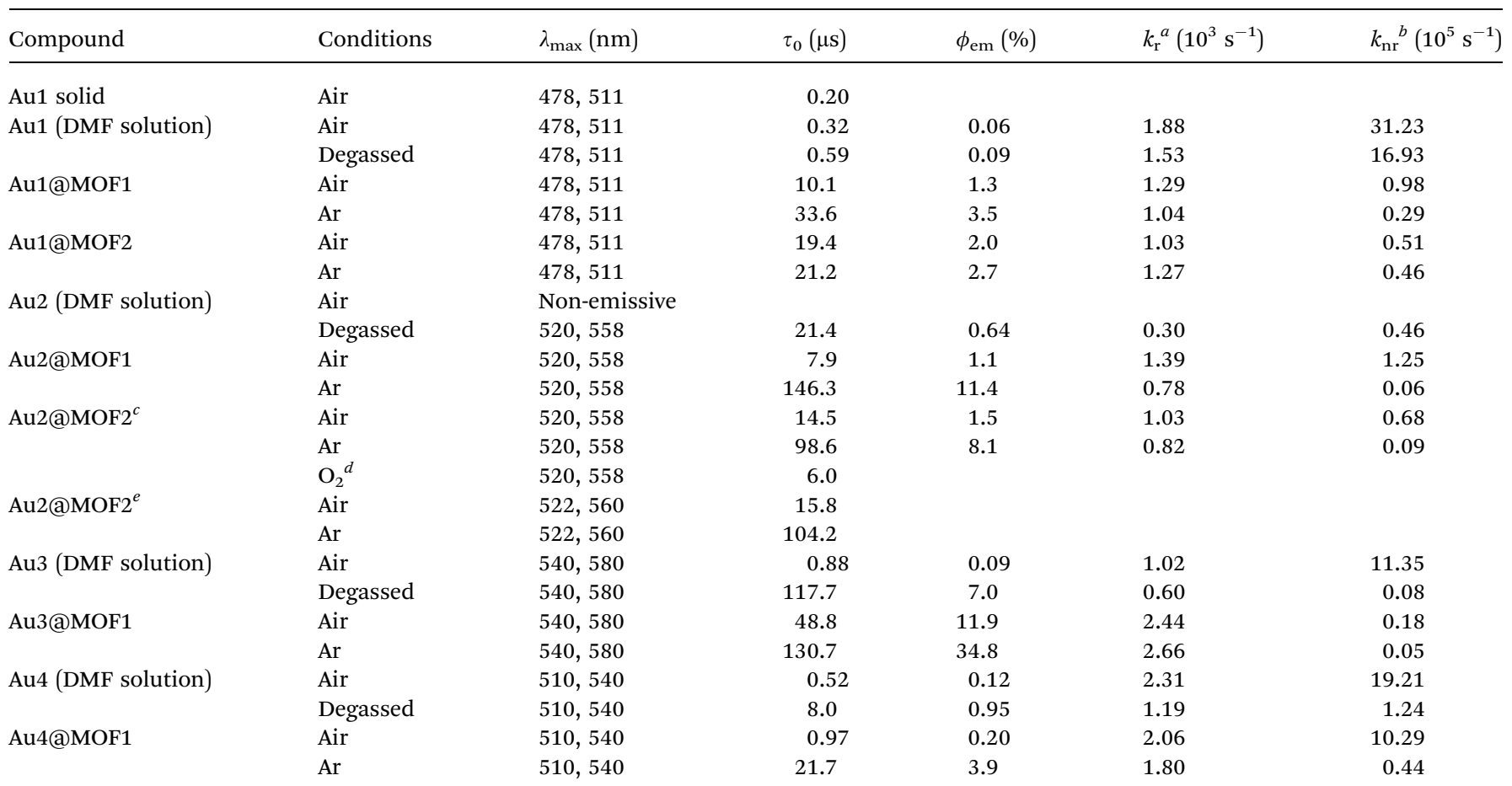

${ }^{a}$ Radiative decay rate constant estimated by $k_{\mathrm{r}}=\phi / \tau .{ }^{b}$ Non-radiative decay rate constant estimated by $k_{\mathrm{nr}}=(1-\phi) / \tau$. ${ }^{c}$ Au2 content: $1.43 \mathrm{wt} \%$. ${ }^{d}$ Au2@MOF2 immersed in acetonitrile saturated with $\mathrm{O}_{2} \cdot{ }^{e}$ Au2 content: $8.26 \mathrm{wt} \%$.

as a terminal oxidant in photo-catalytic reactions within the matrix (see the section below on the photo-catalytic properties of the Au ${ }^{\mathrm{III}} @$ MOF composites) as well as the partial luminescence quenching under aerobic conditions, $\mathrm{O}_{2}$ diffusion in the matrix of Au ${ }^{\mathrm{III}} @ M O F s$ is likely to occur at a finite rate, with the mass transport of $\mathrm{O}_{2}$ through the matrix being sufficiently slow that the above-mentioned equilibrium did not fully occur.

\section{Light-induced electron transfer reactivity of Au2@MOF2}

AuIIIMOFs were observed to display light-induced electron transfer reactivity. As an example, Au2@MOF2 (1.43 wt\% Au2) was first immersed into a solution of methyl viologen dication $\left(\mathrm{MV}^{2+}\right)$ in DMF at room temperature for $12 \mathrm{~h}$ to allow encapsulation of $\mathrm{MV}^{2+}$ inside the pores of the MOF composite, followed by removal of the solution, washing with DMF and drying. Upon xenon lamp $(\lambda>370 \mathrm{~nm})$ irradiation of a mixture of the resulting $\mathrm{Au}^{\mathrm{III}} @ \mathrm{MOF}-\mathrm{MV}^{2+}$ and a drop of $\mathrm{Et}_{3} \mathrm{~N}$ liquid in

(a)

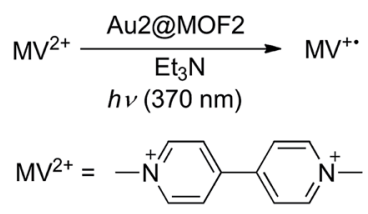

(b)
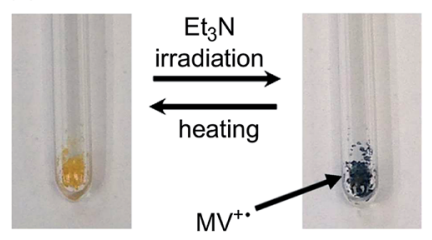

Fig. 3 (a) Photochemical reaction (light source: xenon lamp) between Au2@MOF2 and $\mathrm{MV}^{2+}$, and photographs of the reaction mixture before (b) and after (c) irradiation with light for $1 \mathrm{~min}$. air, the characteristic blue colour of the $\mathrm{MV}^{+}$radical appeared within a few seconds (the colour intensity increased with irradiation time), as depicted in Fig. 3. Heating the mixture (after removing the xenon lamp) to remove $\mathrm{Et}_{3} \mathrm{~N}$ was observed to revert $\mathrm{MV}^{+} \cdot$ back to $\mathrm{MV}^{2+}$, and the photolysis was recycled three times. For comparison, irradiation of a mixture of $\mathrm{Au} 2, \mathrm{MV}^{2+}$ and $\mathrm{Et}_{3} \mathrm{~N}$ in $\mathrm{MeCN}$ under the same aerobic conditions did not give a similar net change in colour of the solution mixture. In fact, a recently reported photochemical reaction of a $\mathrm{Au}^{\text {III }}$ complex with $\mathrm{MV}^{2+}$ was conducted under degassed conditions. ${ }^{8 a}$ We measured the $\mathrm{N}_{2}$ adsorption of Au2@MOF2-MV ${ }^{2+}$ without sample pretreatment, and found that very little $\mathrm{N}_{2}$ could be adsorbed by the sample $\left(\sim 3.7 \mathrm{~cm}^{3} \mathrm{~g}^{-1}\right)$. The corresponding BET surface area is $6.3 \mathrm{~m}^{2} \mathrm{~g}^{-1}$ (Fig. S12, ESI $\dagger$ ), which is quite small compared with the BET surface area of the pretreated Au2@MOF2 (1011 m $\left.\mathrm{g}^{-1}\right)$. Thus, for Au2@MOF2, the observed photochemical reaction with $\mathrm{MV}^{2+}$ and $\mathrm{Et}_{3} \mathrm{~N}$ in air can be attributed to the occurrence of the reaction inside the pores of the MOF composite, which could be occupied by solvent and $\mathrm{Et}_{3} \mathrm{~N}$ molecules, thus decreasing the quenching of $\mathrm{MV}^{+}$by $\mathrm{O}_{2}$.

\section{Two-photon absorption of Au3@MOF1 in the solid state}

Two-photon absorption has useful applications in chemistry and biological science; ${ }^{20,21}$ the two-photon-excited emission of a phosphorescent $\mathrm{Au}^{\mathrm{III}}$ complex in solution has recently been reported. ${ }^{8 a}$ However, there are few reported examples of this property in the solid state, owing to aggregation-induced quenching. ${ }^{21}$ In the present study, we observed that $\mathrm{Au}^{\mathrm{III}}$ @ MOFs display two-photon-induced phosphorescence ${ }^{22}$ in the 
solid state.For Au3@MOF1, excitation at $756 \mathrm{~nm}$ with a focused laser beam gave bright yellow emission (Fig. 4a) with peak maxima at 545 and $585 \mathrm{~nm}$ (characteristic of the emission of Au3) and an intensity showing a quadratic dependence $\left(y=x^{2}\right)$ on the laser power density (Fig. $4 \mathrm{~b}$ and c).

\section{Photo-catalytic properties of Au' @MOF composites}

Cyclometalated $\mathrm{Au}^{\mathrm{III}}$ complexes have recently been reported to sensitize the formation of ${ }^{1} \mathrm{O}_{2}$ upon light excitation for the oxidation of secondary amines to imines and for oxidative cyanation of tertiary amines. ${ }^{7,8 a, 23}$ Using the former as a paradigm, we examined the photo-catalytic activities of $\mathrm{Au}^{\text {III } @ ~}$ MOFs. The photochemical reactions were performed in MeCN. The solution mixture was under light irradiation $(\lambda>400 \mathrm{~nm})$ with constant bubbling of oxygen. Control experiments showed that both MOF1 and MOF2 are stable in MeCN for at least $24 \mathrm{~h}$, as revealed by PXRD measurements (see Fig. S13 of ESI $\dagger$ ). The following was observed: (i) for the photo-reaction with dibenzylamine (Fig. 5), Au1@MOF1 gave the imine product with a turnover number of 692, exceeding the turnover number of 390 obtained with free Au1. The photo-activity of Au1@MOF1 showed little variation over a period of $10 \mathrm{~h}$, whereas free Au1 exhibited a significant decrease in photo-activity after $2 \mathrm{~h}$, with almost no imine product obtained after $6 \mathrm{~h}$ (Fig. 5b). (ii) The Au1@MOF1 catalyst could be recycled by washing with MeCN. After five cycles, the substrate conversion retained a value of $\sim 70 \%$ (Fig. 5 c). (iii) The photo-catalytic activity is attributed to Au1 encapsulated by MOF1 rather than Au1 leached into solution. This is confirmed by the finding that the solution phase of the Au1@MOF1-catalysed reaction mixture remained colourless during the course of photolysis. This is in contrast to the reaction catalysed by free Au1, in which there was a colour change attributed to the decomposition of the Au1 catalyst after $6 \mathrm{~h}$ of photolysis. ICP measurements revealed nearly the same content of gold in the Au1@MOF1 sample before and after photocatalysis; control experiments with MOF1 (free of Au) as the catalyst gave few product turnovers (Fig. 5b). (iv) Substrate size

(a)
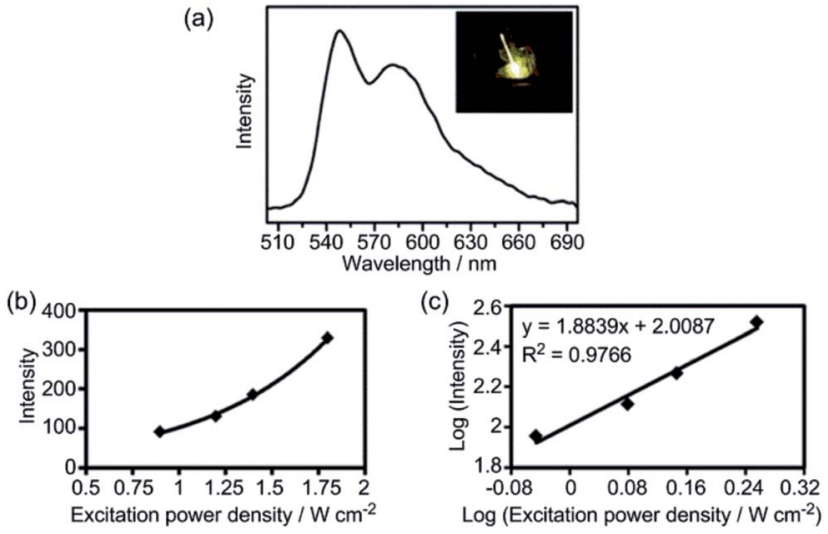

Fig. 4 (a) Emission spectrum of Au3 aMOF1 excited with $756 \mathrm{~nm}$ laser light (inset: photo of the emission of the solid); (b) plot of emission intensity against excitation power density $\left(\mathrm{W} \mathrm{cm}^{-2}\right)$; (c) double-log plot of emission intensity against excitation power density.
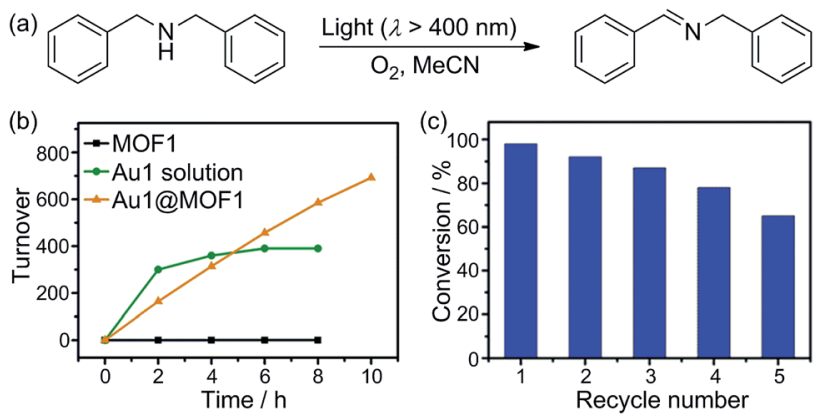

Fig. 5 (a) Photo-catalytic oxidation of dibenzylamine to imine; (b) time course of the oxidation by Au1, MOF1, and Au1@MOF1; (c) substrate conversion in recycling experiments using the Au1@MOF1 catalyst.

selectivity ${ }^{1 b, 2 d}$ was observed for the Au1@MOF1-catalysed competitive photochemical oxidation of dibenzylamine (S1) in the presence of another secondary amine of larger size (S2, Scheme 2). The photochemical reaction consumed S1 rapidly without significant consumption of S2, and the imine products P1 and P2 were formed in a yield ratio of $\sim 11: 1$ for a reaction time of $1.5 \mathrm{~h}$. Under the same conditions, catalyst Au1 showed no selectivity in solution, with a P1/P2 yield ratio of $\sim 1: 1$ (Scheme 2). The drastic difference between the yields of P1 and P2 in the Au1@MOF1-catalysed reaction can be attributed to the reaction mainly occurring inside the channels of the MOF framework. The smaller substrate, S1, could enter the channels of MOF1, but the larger one, S2, could not; the formation of a small amount of $\mathrm{P} 2$ in the reaction mixture is attributed to the external diffusion of singlet oxygen (produced inside the MOF) and its subsequent reaction with S2. Au2@MOF1 and Au3@MOF1 were also found to catalyse the light-induced aerobic oxidation of dibenzylamine (Fig. S14 and S15, ESI $\dagger$ ). The total turnover numbers of the imine product furnished by Au2@MOF1 (0.91 wt\% Au2) and Au3@MOF1 (2.34 wt\% Au3) were 557 and 920 , respectively, and both were higher than the values of 510 and 760 obtained with catalysts $\mathrm{Au} 2$ and $\mathrm{Au} 3$, respectively. The Au2@MOF2 (1.43wt\% Au2) catalyst gave the imine product with turnover number of 610 ; changing the catalyst to Au2@MOF2 (8.26 wt\% Au2) led to a 2-fold increase in conversion rate, albeit with a decrease in product turnover

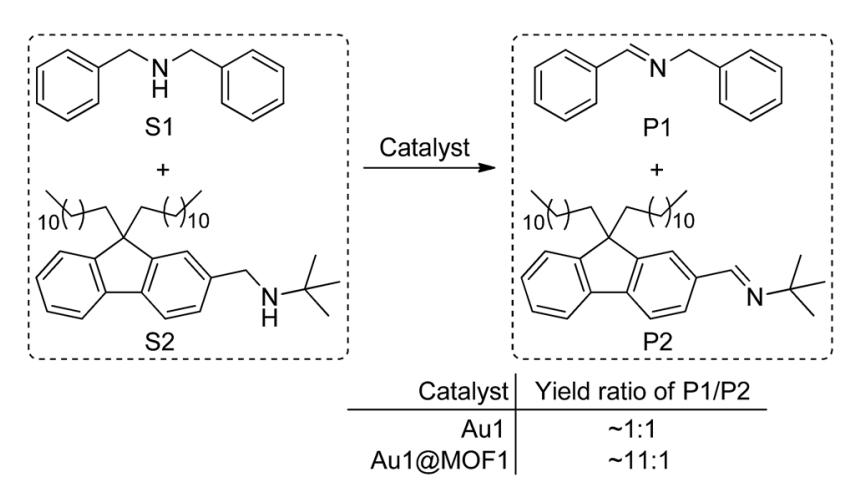

Scheme 2 Competitive photo-catalytic oxidation of secondary amines. 
number (calculated based on \% wt of Au2 in Au2@MOF2; Fig. S16, ESI $\dagger$ ).

The photochemical oxidation of dibenzylamine was also catalysed by Au4 and Au4@MOF1 (Au4: $6 \times 10^{-7}$ mol in both cases).Au4@MOF1 was a more active catalyst with a turnover number of $>143$ attained within $2 \mathrm{~h}$ (Fig. 6a). Notably, the initial reaction rate of the Au4@MOF1 system was two-fold higher than that of Au4 alone. After recycling five times, the photoactivity of the Au4@MOF1 catalyst maintained $~ 80 \%$ of its initial value (Fig. 6b). Increasing the content of Au4 in solution from $6 \times 10^{-7}$ to $6 \times 10^{-6} \mathrm{~mol}$ decreased the product turnover number from 90 to 18 (Fig. 6a).

The improvement in photo-catalytic activity of $\mathrm{Au}^{\mathrm{III}} @ \mathrm{MOFs}$ relative to the free $\mathrm{Au}^{\mathrm{III}}$ complexes could be extended to the oxidative cyanation of a tertiary amine, a Mannich-type reaction, the aza-Henry reaction, the hydroxylation of 4-chlorophenylboronic acid, and the reductive cyclization of alkyl iodide. ${ }^{24}$ These findings are depicted in Scheme 3 and in Fig. S17 and Tables S3-5 of the ESI. $\dagger$ For example, the steady formation of product was observed over $8 \mathrm{~h}$ in the Au1@MOF1-catalysed oxidative cyanation of $N$-phenyl-1,2,3,4-tetrahydroisoquinoline, in contrast to a significant decrease in the activity of the free Au1 catalyst after $2.5 \mathrm{~h}$ of photolysis (Fig. S17, ESI $\dagger$ ). The product yield obtained with the Au1@MOF1 catalyst was 81\% (turnover number of 923). For the other photochemical reactions with Au2@MOF2 (1.43 wt $\% \mathrm{Au} 2$ ) as catalyst, the products were obtained in $63-86 \%$ yields with turnover numbers of 137-549. These values were higher than the corresponding product yields and turnover numbers obtained with Au2 alone (Tables S3-S5, ESI $\dagger$ ).

To gain further insight into the photochemical oxidation reactions catalysed by $\mathrm{Au}^{\mathrm{III}} @ \mathrm{MOFs}$ under aerobic conditions, which are likely to involve the formation of ${ }^{1} \mathrm{O}_{2},{ }^{7,23 b}$ we measured the reduction potentials, $E\left(\mathrm{Au}^{0 /-}\right)$, of Au1-Au4 (Table S6, ESI $\dagger$ ) and estimated the excited state reduction potentials, $E\left(\mathrm{Au}^{*} / \mathrm{Au}^{-}\right)$, from the electrochemical and emission data. The estimated $E\left(\mathrm{Au}^{*} / \mathrm{Au}^{-}\right)$values of $\mathrm{Au} 1-\mathrm{Au} 4$ range from +0.74 to $+1.38 \mathrm{~V}$ vs. $\mathrm{Cp}_{2} \mathrm{Fe}^{+/ 0}$ (Table S6, ESI $\dagger$ ), indicating that they are strong oxidants in the excited state. The potentials of dibenzylamine and $N$-phenyl-1,2,3,4-tetrahydroisoquinoline, $E\left(\right.$ amine $\left.^{+/ 0}\right)$, were measured to be $+0.50 \mathrm{~V}$ and $+0.25 \mathrm{~V}$ vs. $\mathrm{Cp}_{2} \mathrm{Fe}^{+/ 0}$, respectively. Thus, the thermodynamic driving force for the reaction of the excited Au1-Au4 with dibenzylamine was estimated to be in the range of +0.24 to $+0.88 \mathrm{~V}$, whereas that of the excited Au2
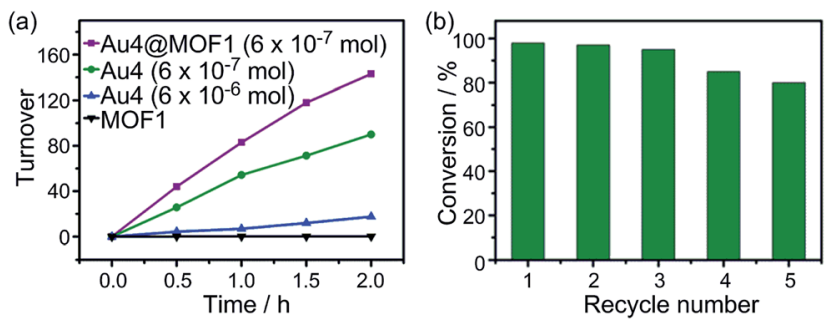

Fig. 6 (a) Product turnovers in the photo-catalytic oxidation of dibenzylamine to imine by MOF1, Au4@MOF1, and Au4 solution; (b) substrate conversion in recycling experiments using the Au4@MOF1 catalyst.

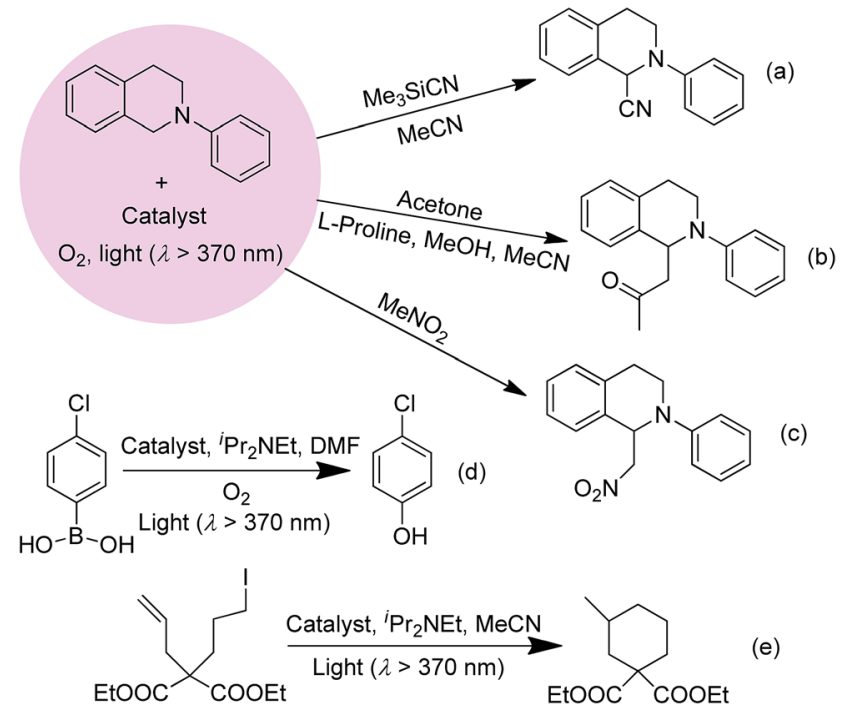

Scheme 3 Photo-catalytic oxidative cyanation of a tertiary amine (a), Mannich-type reaction (b), aza-Henry reaction (c), hydroxylation of 4-chlorophenylboronic acid (d), and reductive cyclization of alkyl iodide (e) catalysed by $\mathrm{Au}^{\text {III }}$ aMOFs.

complex with $N$-phenyl-1,2,3,4-tetrahydroisoquinoline is +0.49 V. Nanosecond time-resolved transient absorption (TA) measurements (Table S7, ESI $\dagger$ ) revealed that, in the presence of dibenzylamine (0.1 M) in degassed DMF, the TA of Au2 and Au3 was quickly quenched ( $\tau_{\mathrm{TA}}: 1.4 \mu \mathrm{s}$ for Au2, $2.2 \mu \mathrm{s}$ for Au3) and returned to the baseline, whereas the TA of Au1 and Au4 evolved to give long-lived species ( $\tau_{\mathrm{TA}}: 145 \mu \mathrm{s}$ for Au1, $24 \mu \mathrm{s}$ for $\mathrm{Au} 4$ ), attributable to the formation of $\mathrm{Au} 1^{-}$and $\mathrm{Au} 4^{-} .{ }^{25}$ The TA spectrum of Au2 in the presence of $N$-phenyl-1,2,3,4-tetrahydroisoquinoline $(0.01 \mathrm{M})$ shows the formation of a long-lived species $(\tau=65 \mu \mathrm{s})$ assignable to Au2 $2^{-}$(Table S8, ESI $\dagger$ ). Thus, in the photochemical oxidation of dibenzylamine catalysed by Au1 and $\mathrm{Au} 4$, and that of $\mathrm{N}$-phenyl-1,2,3,4-tetrahydroisoquinoline catalysed by $\mathrm{Au} 2$, the excited gold(III) complexes may undergo electron transfer with the amines (to give amine radical cations) besides producing singlet oxygen for oxidation.

\section{Conclusions}

A series of luminescent $\mathrm{Au}^{\mathrm{III}}$-encapsulated MOF composites (Au'IIIMOFs) have been synthesized. These Au ${ }^{\text {III } @ M O F ~ s o l i d s ~}$ exhibit long emission lifetimes in air, display solid state twophoton-induced phosphorescence, and function as reusable and size-selective heterogeneous photo-catalysts. The simple approach of incorporating phosphorescent metal complexes with long-lived emissive excited states into MOFs provides a means of developing new classes of heterogeneous photofunctional materials/photo-catalysts with useful applications.

\section{Acknowledgements}

This work was supported by the Hong Kong Research Grants Council (HKU 7008/09P), the University Grants Committee 
Areas of Excellence Scheme (AoE/P-03/08), the National Key Basic Research Program of China (no. 2013CB834802), the NSFC/RGC Joint Research Scheme (N_HKU 752/08), and the CAS-Croucher Funding Scheme for Joint Laboratories. We thank Prof. Dr Ya-Qian Lan, Dr Ji-Qiang Ning, and Dr Han Wu for assistance in $\mathrm{N}_{2}$ sorption, two-photon absorption, and ICP measurements, respectively.

\section{Notes and references}

1 (a) H.-C. J. Zhou and S. Kitagawa, Chem. Soc. Rev., 2014, 43, 5415-5418; (b) H. Furukawa, K. E. Cordova, M. O'Keeffe and O. M. Yaghi, Science, 2013, 341, 1230444.

2 (a) J. Liu, L. Chen, H. Cui, J. Zhang, L. Zhang and C.-Y. Su, Chem. Soc. Rev., 2014, 43, 6011-6061; (b) T. Zhang and W. Lin, Chem. Soc. Rev., 2014, 43, 5982-5993; (c) Z. Hu, B. J. Deibert and J. Li, Chem. Soc. Rev., 2014, 43, 58155840; (d) A. Corma, H. García, F. X. Llabrés and i. Xamena, Chem. Rev., 2010, 110, 4606-4655.

3 S. M. Cohen, Chem. Rev., 2012, 112, 970-1000.

4 (a) J. D. Evans, C. J. Sumby and C. J. Doonan, Chem. Soc. Rev., 2014, 43, 5933-5951; (b) J. Juan-Alcañiz, J. Gascon and F. Kapteijn, J. Mater. Chem., 2012, 22, 10102-10118.

5 (a) J. Schneider, M. Matsuoka, M. Takeuchi, J. Zhang, Y. Horiuchi, M. Anpo and D. W. Bahnemann, Chem. Rev., 2014, 114, 9919-9986; (b) X. Qian, K. Fuku, Y. Kuwahara, T. Kamegawa, K. Mori and H. Yamashita, ChemSusChem, 2014, 7, 1528-1536; (c) X.-d. Wang and O. S. Wolfbeis, Chem. Soc. Rev., 2014, 43, 3666-3761; (d) J. Feng and H. Zhang, Chem. Soc. Rev., 2013, 42, 387-410; (e) B. Yan, RSC Adv., 2012, 2, 9304-9324; (f) L. D. Carlos, R. A. S. Ferreira, V. de Zea Bermudez and S. J. L. Ribeiro, Adv. Mater., 2009, 21, 509-534; (g) P. Escribano, B. JuliánLópez, J. Planelles-Aragó, E. Cordoncillo, B. Viana and C. Sanchez, J. Mater. Chem., 2008, 18, 23-40.

6 (a) Y. Yamada, A. Nomura, K. Ohkubo, T. Suenobu and S. Fukuzumi, Chem. Commun., 2013, 49, 5132-5134; (b) H. O. Lintang, K. Kinbara, K. Tanaka, T. Yamashita and T. Aida, Angew. Chem., Int. Ed., 2010, 49, 4241-4245; (c) R. Nakamura, A. Okamoto, H. Osawa, H. Irie and K. Hashimoto, J. Am. Chem. Soc., 2007, 129, 9596-9597; (d) K. Feng, R.-Y. Zhang, L.-Z. Wu, B. Tu, M.-L. Peng, L.-P. Zhang, D. Zhao and C.-H. Tung, J. Am. Chem. Soc., 2006, 128, 14685-14690; (e) K. Inumaru, T. Kasahara, M. Yasui and S. Yamanaka, Chem. Commun., 2005, 21312133; ( $f$ ) H. Yamashita, K. Yoshizawa, M. Ariyuki, S. Higashimoto, M. Che and M. Anpo, Chem. Commun., 2001, 435-436.

7 W.-P. To, G. S.-M. Tong, W. Lu, C. Ma, J. Liu, A. L.-F. Chow and C.-M. Che, Angew. Chem., Int. Ed., 2012, 51, 2654-2657.

8 (a) W.-P. To, K. T. Chan, G. S. M. Tong, C. Ma, W.-M. Kwok, X. Guan, K.-H. Low and C.-M. Che, Angew. Chem., Int. Ed., 2013, 52, 6648-6652; (b) H.-M. Ko, K. K.-Y. Kung, J.-F. Cui and M.-K. Wong, Chem. Commun., 2013, 49, 8869-8871; (c) J. J. Yan, A. L.-F. Chow, C.-H. Leung, R. W.-Y. Sun, D.-L. Ma and C.-M. Che, Chem. Commun., 2010, 46, 3893-3895.

9 D. T. Genna, A. G. Wong-Foy, A. J. Matzger and M. S. Sanford, J. Am. Chem. Soc., 2013, 135, 10586-10589.

10 X. Zhang, F. X. Llabrés, i. Xamena and A. Corma, J. Catal., 2009, 265, 155-160.

11 J. Muzart, Tetrahedron, 2009, 65, 8313-8323.

12 V. A. Blatov and M. V. Peskov, Acta Crystallogr., Sect. B: Struct. Sci., 2006, 62, 457-466.

13 A. Spek, J. Appl. Crystallogr., 2003, 36, 7-13.

14 K. S. W. Sing, D. H. Everett, R. A. W. Haul, L. Moscou, R. A. Pierotti, J. Rouquérol and T. Siemieniewska, Pure Appl. Chem., 1985, 57, 603-619.

15 C.-Y. Sun, C. Qin, C.-G. Wang, Z.-M. Su, S. Wang, X.-L. Wang, G.-S. Yang, K.-Z. Shao, Y.-Q. Lan and E.-B. Wang, Adv. Mater., 2011, 23, 5629-5632.

16 Y.-A. Li, S.-K. Ren, Q.-K. Liu, J.-P. Ma, X. Chen, H. Zhu and Y.-B. Dong, Inorg. Chem., 2012, 51, 9629-9635.

17 (a) C. L. Whittington, L. Wojtas and R. W. Larsen, Inorg. Chem., 2014, 53, 160-166; (b) G.-S. Yang, M.-N. Li, S.-L. Li, Y.-Q. Lan, W.-W. He, X.-L. Wang, J.-S. Qin and Z.-M. Su, J. Mater. Chem., 2012, 22, 17947-17953; (c) R. W. Larsen, J. Miksovska, R. L. Musselman and L. Wojtas, J. Phys. Chem. A, 2011, 115, 11519-11524.

18 H. Yersin, A. F. Rausch, R. Czerwieniec, T. Hofbeck and T. Fischer, Coord. Chem. Rev., 2011, 255, 2622-2652.

19 (a) P. Duan, N. Yanai and N. Kimizuka, J. Am. Chem. Soc., 2013, 135, 19056-19059; (b) J.-H. Kim, F. Deng, F. N. Castellano and J.-H. Kim, Chem. Mater., 2012, 24, 2250-2252.

20 (a) G. Bort, T. Gallavardin, D. Ogden and P. I. Dalko, Angew. Chem., Int. Ed., 2013, 52, 4526-4537; (b) S. Sumalekshmy and C. J. Fahrni, Chem. Mater., 2011, 23, 483-500; (c) M. Pawlicki, H. A. Collins, R. G. Denning and H. L. Anderson, Angew. Chem., Int. Ed., 2009, 48, 3244-3266.

21 (a) H.-H. Fang, Q.-D. Chen, J. Yang, H. Xia, B.-R. Gao, J. Feng, Y.-G. Ma and H.-B. Sun, J. Phys. Chem. C, 2010, 114, 1195811961; (b) J. Yu, Y. Cui, H. Xu, Y. Yang, Z. Wang, B. Chen and G. Qian, Nat. Commun., 2013, 4, 2719-2725.

22 Q. Zhao, C. Huang and F. Li, Chem. Soc. Rev., 2011, 40, 25082524.

23 (a) Q.-C. Xue, J. Xie, H.-M. Jin, Y.-X. Cheng and C.-J. Zhu, Org. Biomol. Chem., 2013, 11, 1606-1609; (b) T. N. Zehnder, O. Blacque and K. Venkatesan, Dalton Trans., 2014, 43, 11959-11972.

24 (a) D. M. Schultz and T. P. Yoon, Science, 2014, 343, 1239176; (b) C. K. Prier, D. A. Rankic and D. W. C. MacMillan, Chem. Rev., 2013, 113, 5322-5363.

25 P.-K. Chow, G. Cheng, G. S. M. Tong, W.-P. To, W.-L. Kwong, K.-H. Low, C.-C. Kwok, C. Ma and C.-M. Che, Angew. Chem., Int. Ed., 2015, 54, 2084-2089. 